Research Article

\title{
Fatty Amidine as Copper Corrosion Inhibitor
}

\author{
Zainal Alim Mas'ud, ${ }^{1,2}$ Noviyan Darmawan $\mathbb{D}^{1,2}{ }^{1,2}$ Januari Dawolo, ${ }^{1}$ \\ and Yusuf Bramastya Apriliyanto $\mathbb{D}^{1,3}$ \\ ${ }^{1}$ Department of Chemistry, IPB University, Jl. Tanjung Kampus IPB Dramaga, Bogor 16680, Indonesia \\ ${ }^{2}$ Halal Science Center LPPM, IPB University, Jl. Pajajaran Kampus IPB Baranangsiang, Bogor 12230, Indonesia \\ ${ }^{3}$ Department of Chemistry, Indonesia Defense University, Kampus Unhan Komplek IPSC Sentul, Bogor 16680, Indonesia
}

Correspondence should be addressed to Noviyan Darmawan; noviyandarmawan@apps.ipb.ac.id

Received 23 August 2020; Accepted 22 October 2020; Published 4 November 2020

Academic Editor: Mallikarjuna N. Nadagouda

Copyright ( $) 2020$ Zainal Alim Mas’ud et al. This is an open access article distributed under the Creative Commons Attribution License, which permits unrestricted use, distribution, and reproduction in any medium, provided the original work is properly cited.

\begin{abstract}
The development of green and sustainable corrosion inhibitors for copper in a corrosive marine environment is highly desired. Herein, we studied the fatty acid-based amidine as the new type of renewable corrosion inhibitor. Stearamidine salt was used as a model inhibitor, and it was synthesized through stearonitrile intermediate with an excellent isolated yield of $88 \%$. We used electrochemical (potentiodynamic polarization) and morphological (scanning electron microscopy) measurements to assess the corrosion inhibition efficiency of stearamidine in $3.0 \mathrm{wt} . \% \mathrm{NaCl}$ at $300 \mathrm{~K}$. We show that, in such a condition, the optimum inhibition efficiency of $96 \%$ was achieved using only $0.2 \mathrm{mM}$ stearamidine. The results suggested the fatty amidine is a promising corrosion inhibitor for copper that is suitable in the saltwater ecosystem. The thermodynamic parameters of the interaction between the stearamidine and the copper surface were determined, and the result suggests that the adsorption process occurred accordingly with the Langmuir adsorption isotherm and involved both physisorption and chemisorption.
\end{abstract}

\section{Introduction}

Materials based on copper and copper alloys are commonly used for various types of industrial equipment. These materials offer a particular advantage in a combination of thermal and/ or electrical conductivity, mechanical workability, and it is relatively inert [1]. They are typically applied as heat exchangers, power plant condensers, water-cooling systems, desalination plants, and shipboard condensers. Copper and copper alloys are prone to corrosion in various environments, especially in marine environments. The corrosion on copper and its alloys takes place at a higher rate in the presence of high concentration of salt ions, which will culminate in the structural rupture and create enormous economic losses. The addition of corrosion inhibitors on the metal surfaces is one of the most effective, economical, and conventional approaches to prevent this detrimental process [1-3].

The aim to add corrosion inhibitor on a metal surface, usually in low concentration, is to effectively minimize the corrosion rate of the substrate in a specific environment, such as the highly corrosive marine ecosystem. Some organic molecules have been reported as potential compounds that can effectively inhibit corrosion for various metals and metal alloys, including copper and its alloys [4]. These compounds show high inhibiting properties due to their adsorption affinity with copper surfaces through intermolecular interactions [5]. It has been known that the chemical structure, the adsorption mode, and the surface charge of metals, including the type of electrolyte solution, are the key points governing the interactions of molecules on the surfaces of metals [6]. It is not surprising that the reported corrosion inhibitor compounds are derived from azoles, imidazoles, triazoles, indazole, oxazole, thiadiazole, and quinoline framework [7-13]. These inhibitors contain heteroatom centres such as sulphur, oxygen, and nitrogen acting as their major adsorption sites. Due to the inevitable trend toward environmentally friendly and sustainable processes, current research is focused on the development of green corrosion inhibitors [14-18]. One type of compound that shows promising potential as a corrosion inhibitor of copper is the 
derivatization of oleochemicals that can be obtained from a renewable source such as the palm oil industry. The presence of long alkyl chains can help to form a protective layer and the terminal moiety that can be easily manipulated to tune the binding properties on metal surfaces.

Fatty acid derivates are inexpensive, abundant, and ideal candidates as precursor materials for producing sustainable and green chemicals $[19,20]$. There are numerous reports regarding the corrosion inhibitors for metal surfaces based on the fatty acid derivatives, including acyclic and heterocyclic compounds [21-31]. Interestingly, there are no reports of fatty amidine as a corrosion inhibitor. Amidine is a derivative of oxoacid with the general structure of the $\mathrm{RnC}$ (=NR)NR2, wherein the hydroxyl group and oxo group were substituted by an amino group and imine group, respectively [32].

In the present study, we use stearamidine hydrochloride salt as a model compound to evaluate the potential corrosion inhibition of fatty amidine on a copper surface. To assess the corrosion inhibition efficiency of stearamidine in $3.0 \mathrm{wt} \%$ $\mathrm{NaCl}$, we used electrochemical and morphological analysis. The thermodynamic parameters were also calculated and discussed, and thus the nature of their interaction is also elucidated.

\section{Methods}

2.1. Materials. All chemical reagents were brought from commercial sources without further purification. Characterizations were conducted by FTIR (IR Prestige-21) and GC (GC 2010) from Shimadzu. NMR spectra were measured using an ECA 500 JEOL. The chemical shifts $(\delta)$ of $1 \mathrm{H} \mathrm{NMR}$ were showed in the unit of ppm, and the value of Hertz $(\mathrm{Hz})$ is used for the coupling constants $(J)$. The referenced chemical shift of deuterated solvents is CD3OD (3.31 ppm) and $\mathrm{CDCl} 3$ (7.26 ppm). The electrochemistry measurements were conducted on a $\mathrm{CH} 750$ potentiostat from $\mathrm{CH}$ Instrument workstation. Silver $(\mathrm{Ag} / \mathrm{AgCl})$, platinum $(\mathrm{Pt})$, and copper $(\mathrm{Cu})$ were used as the reference, counter, and working electrodes, respectively.

\subsection{Procedure}

2.2.1. Stearonitrile. Stearic acid $(60.2 \mathrm{~g}, 0.211 \mathrm{~mol})$ was put into a two-neck flask and was melted at $80^{\circ} \mathrm{C}$ under nitrogen atmosphere. Urea (30 g, $0.499 \mathrm{~mol}$ ) was put in gradually, and then the flask is heated with vigorous stirring at $300^{\circ} \mathrm{C}$ for $6 \mathrm{~h}$. The reaction progress was monitored by TLC analysis. After the reaction is complete, the subsequent mixture was filtered through Celite. The filtrates were separated by recrystallization. Further purification was done with column chromatography by using a solvent mixture of $n$-hexane and ethyl acetate with 6:1 ratio. The final compound was obtained as off-white solid, and the yield is $92 \%$. Melting point was $40-41^{\circ} \mathrm{C}$ (stearonitrile standard: $\left.41-41.5^{\circ} \mathrm{C}\right)$. FTIR (KBr) Ú was $2249 \mathrm{~cm}^{-1}$ (stretch $\left.\mathrm{C} \equiv \mathrm{N}\right), 2920$, and $2851 \mathrm{~cm}^{-1}$ (stretch C-C and C-H, respectively). $1 \mathrm{H} \mathrm{NMR} \mathrm{(500} \mathrm{MHz,}$ $\mathrm{CHCl} 3) \delta$ was $2.33(\mathrm{t}, 2 \mathrm{H}) ; 1.63(\mathrm{~m}, 2 \mathrm{H}) ; 1.39(\mathrm{~m}, 2 \mathrm{H}) ; 1.25$ $(\mathrm{s}, 26 \mathrm{H})$; and $0.95(\mathrm{t}, 3 \mathrm{H})$. Purity was examined by GC: $98 \%$.
2.3. Synthesis of Stearamidine Hydrochloride. A total of $3 \mathrm{~g}$ stearonitrile compound was dissolved in $33 \mathrm{~mL}$ of methanoldiethyl ether mixture. Dried hydrochloric acid gas $(\mathrm{HCl})$ was passed through the solution for two hours at $0^{\circ} \mathrm{C}$ and then cooled to $-20^{\circ} \mathrm{C}$ for 96 hours. The solvent was evaporated to produce imide hydrochloride and then washed with cold diethyl ether solution. Imide hydrochloride was treated with $100 \mathrm{~mL}$ of ammonia in methanol (NH3/MeOH 7N, 5 eq.). The obtained filtrate was then separated by filtration and evaporation to obtain stearamidine hydrochloride salt as offwhite solid. The yield was $88.2 \%$. FTIR (KBr) Ú, in $\mathrm{cm}^{-1}$, was 3215 (stretch N-H), 3000 to 2800 (stretch C-C and C-H), $1648(\mathrm{C}=\mathrm{N}$ symmetric vibration), 1415 (stretch $\mathrm{C}=\mathrm{N}$ ), and 1092 (stretch C-N), and 1H NMR (500 MHz, CD3OD) $\mathrm{J}=2.46(\mathrm{t}, 2 \mathrm{H}), 1.70(\mathrm{~m}, 2 \mathrm{H}) ; 1.35(\mathrm{~m}, 28 \mathrm{H})$; and $0.86(\mathrm{t}, 3 \mathrm{H})$.

2.4. Corrosion Inhibition Measurement. The electrochemical scan was conducted from cathode to anode with potential in the range of -400 to $+400 \mathrm{mV}$ vs. saturated calomel electrode (SCE) at $0.5 \mathrm{mV} \mathrm{s}^{-1}$ sweep rate at three different temperatures $(300,313$, and $333 \mathrm{~K}$ ) by using various concentrations of stearamidine. The measured current density was used for the calculation of corrosion inhibition efficiency $(\eta)$ by using the formula as follows:

$$
\eta(\%)=\left(\frac{i_{\text {corr }}^{0}-i_{\text {corr }}}{i_{\text {corr }}^{0}}\right) \times 100 \%,
$$

where the efficiency of inhibition is $\eta(\%)$, the current density in blank solution is $i_{\text {corr }}$, while the current density in a solution with the presence of stearamidine is $i_{\text {corr }}^{0}$. The sample with optimum inhibition efficiency was then analyzed for its surface morphology by using SEM, and its surface micrograph was compared with the corresponding blank sample.

\section{Results and Discussion}

3.1. Synthesis and Characterization of Stearamidine Hydrochloride. We used stearamidine as a model compound to evaluate the potential application of fatty amidine as a green copper corrosion inhibitor. Stearamidine salt was synthesized from free fatty acid in two steps of reaction. Scheme 1 shows the reaction route for the synthesis of stearamidine. Based on Scheme 1, firstly, stearic acid was reacted with urea at $300^{\circ} \mathrm{C}$ for 2 hours to afford stearonitrile as off-white solid [33]. The GC analysis of the synthesized stearonitrile revealed that the purity of the product was very high, around 98\%. After the nitrile was obtained, the preparation of stearamidine salt was conducted via Pinner synthesis developed by Baker et al. [34]. The treatment of nitriles with gaseous $\mathrm{HCl}$ in a mixture of anhydrous ether and methanol produced an imino ester. Then, the salt was reacted with ammonia to obtain amidine hydrochloride. The completion of reaction was indicated by the presence of a new spot at the $R_{f}$ value about 0.41 and the disappearance of the spot corresponding to stearonitrile $\left(R_{f}\right.$ of 0.83$)$ (see Figure $1(\mathrm{a})$ ). The product after purification was isolated as a white solid with a good reaction yield of $88 \%$. 


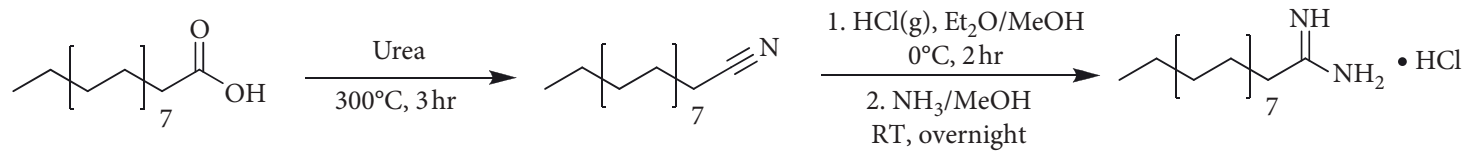

SCHEME 1: Synthesis route of stearamidine.
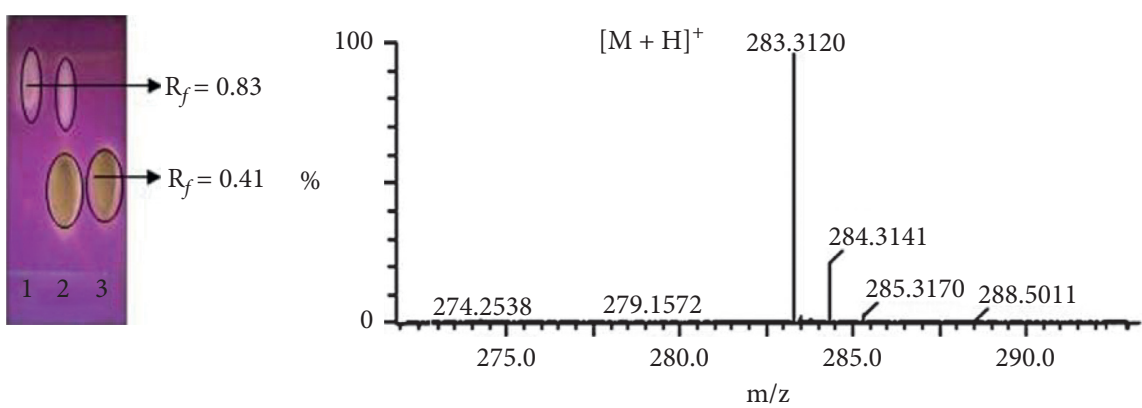

(a)

(b)

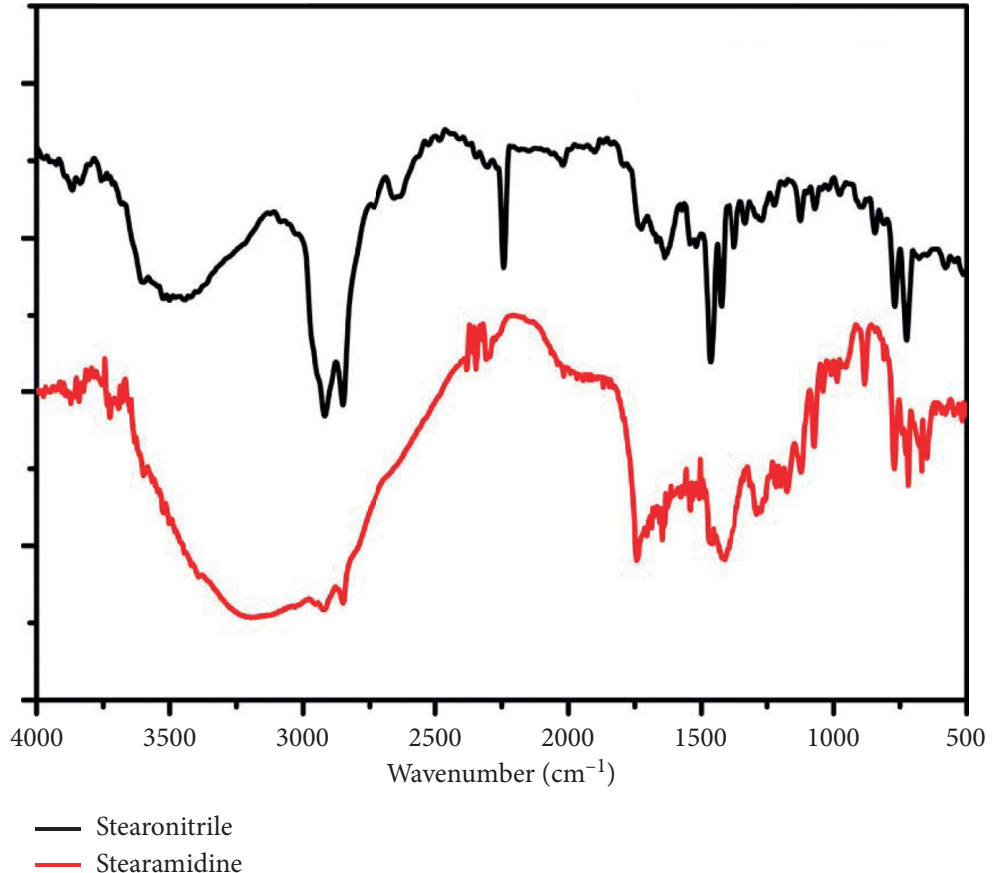

(c)

FIgURE 1: (a) TLC of reaction crude ( 1 = precursor, 2 = cospot, and 3 = reaction crude). (b) ESI MS of stearamidine. (c) FTIR spectra of stearonitrile (black) and stearamidine (red).

In Figure 1(b), the ESI mass spectrum of the isolated product confirms that the isolated compound is stearamidine with one major peak at $283.312 \mathrm{~m} / \mathrm{z}$, which is in good agreement with the calculated MW of stearamidine [M $+\mathrm{H}]+$. FTIR spectrum of synthesized stearamidine is presented in Figure 1(c). The broad peaks in the region ranging from 3200 to $3500 \mathrm{~cm}^{-1}$ belong to the $\mathrm{N}-\mathrm{H}$ stretching vibrations, and these bands are not detected in the FTIR spectrum of stearonitrile. On the other hand, the lacking of the $\mathrm{CN}$ stretch band in the region of $2210-2260 \mathrm{~cm}^{-1}$ indicates that the conversion of nitrile is completed. Moreover, the bands corresponding to the presence of- $\mathrm{CH} 2$ - groups at
2870 and $2956 \mathrm{~cm}^{-1}$ are also detected. Furthermore, to verify that stearamidine was obtained, we investigated the NMR spectra of the product. The proton NMR analysis confirms that the product is stearamidine. As can be seen from Figure 2, four distinct peaks are observed in the NMR spectra and correspond to four different types of hydrogen that are present in stearamidine, with $\mathrm{J}=2.46(\mathrm{t}, 2 \mathrm{H}) ; 1.70$ $(\mathrm{m}, 2 \mathrm{H}) ; 1.35(\mathrm{~m}, 28 \mathrm{H})$; and $0.86(\mathrm{t}, 3 \mathrm{H})$, respectively.

The polarization curves of samples were measured in 3.0 wt. $\% \mathrm{NaCl}$ solution at $300 \mathrm{~K}$ with various concentrations of stearamidine (Figure 3). The electrochemical parameters were then calculated from the corresponding polarisation 


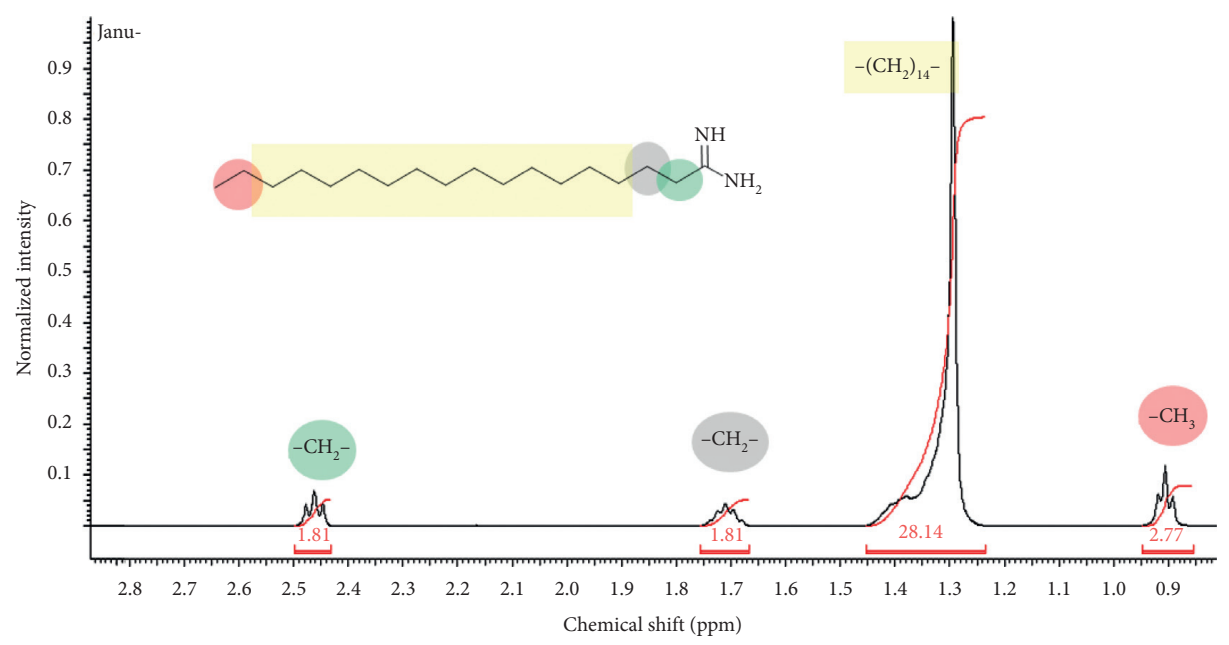

FIGURE 2: Proton NMR spectra of the product. Inhibition performance: potentiodynamic polarisation and SEM imaging.

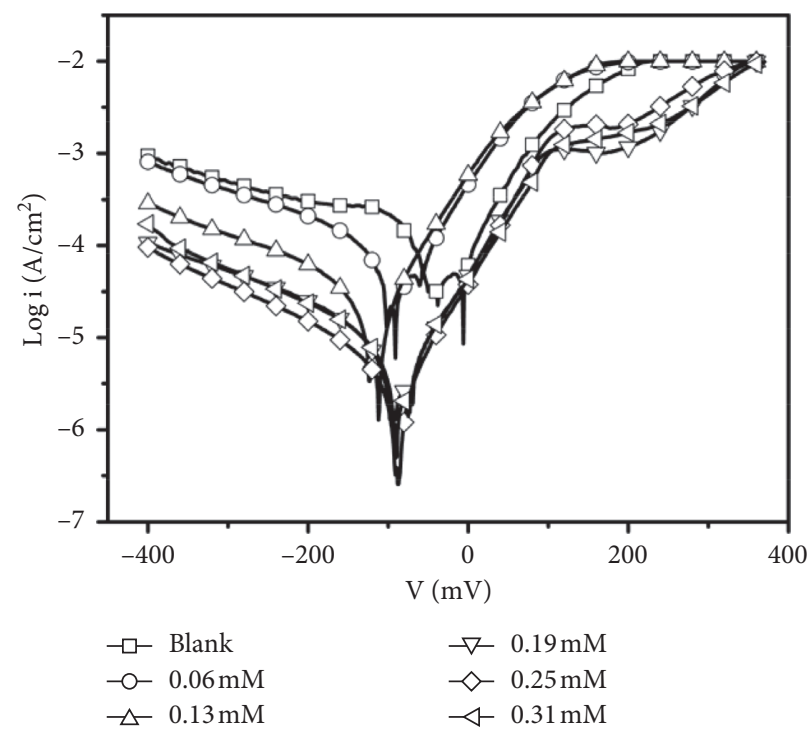

FIGURe 3: Potentiodynamic polarization curves of $\mathrm{Cu}$ in $3.0 \mathrm{wt} . \%$ $\mathrm{NaCl}$ solution at $300 \mathrm{~K}$ with a variety of concentrations of stearamidine.

curves (Table 1). In the blank solution, it was observed that the anodic current density consistently increased with potential (see Figure 3 ) and is in good agreement with previous reports $[8,12]$. This result represents the dissolution of the $\mathrm{Cu}$ electrode to generate soluble species, i.e., $\mathrm{CuCl}_{2}$. The current density then decreases after reaching a maximum point. This trend corresponds to the formation and arrangement of the $\mathrm{CuCl}$ thin film. Dissolution of this thin deposition to produce $\mathrm{Cu}(\mathrm{II})$ ions further increases the current density again. In contrast, the addition of stearamidine leads to a substantial drop in the corrosion rate. The presence of stearamidine shifts and decrease in cathodic and anodic current densities hence inhibits the corrosion rate in comparison with the blank solution at the corresponding individual potential (Figure 3).

The anodic and cathodic reaction mechanisms were not changed by the addition of stearamidine as the inhibitor, as each curve in Figure 3 was found to be parallel to each other. This result indicated that stearamidine adsorbed on the copper surfaces act as a protective layer providing a high degree of protection from the corrosion process [3]. Moreover, the change of Ecorr value in the presence of stearamidine is less than $85 \mathrm{mV}$ in comparison with the blank solution. This result confirms that stearamidine is a mixed-type corrosion inhibitor [35]. With the increasing of stearamidine concentration, we found a drop in the value of corrosion current density. At the same time, there was an increase of the inhibition efficiency (EI) and reached a maximum value of $96 \%$ when using $0.2 \mathrm{mM}$ stearamidine in 3.0 wt. $\% \mathrm{NaCl}$ solution at $300 \mathrm{~K}$ (Table 1 ). The increase of EI with the concentration is expected because with an increase in the number of stearamidine molecules, more corrosion sites can be blocked. Amidine moieties possess a donor electron group from the lone electron pair of the nitrogen atom. This lone pair can be donated to the positively charged copper surfaces forming a strong coordination bond that ensures excellent inhibition efficiency.

To elucidate the influence of temperature on the corrosion inhibition properties, calculated inhibition efficiency (EI), and corrosion rate (CR) of the stearamidine, the electrochemical measurement was conducted by varying the concentration of stearamidine at applied temperatures, in the range of 300 to $333 \mathrm{~K}$ (Figure 4). The result indicated that temperature has a damaging impact on the ability of stearamidine to inhibit the corrosion process. As the temperature increases, the EI value decreases significantly while the corrosion rate increases. This phenomenon is mainly due to the properties of organic molecules, in which the adsorption capacity is weakened at high temperatures. At high temperatures, adsorption and desorption rates from the metal surface are relatively high. Besides, at high temperatures, the organic-based inhibitor compounds are possible to be decomposed [6]. We also investigated the effect of stearamidine on the surface morphology of copper. The SEM micrographs of copper with and without the addition of stearamidine are presented in Figure 5. Clearly, Figure 5 shows that the addition of stearamidine as corrosion 
TABLE 1: Electrochemical parameters of $\mathrm{Cu}$ in $3.0 \mathrm{wt} . \% \mathrm{NaCl}$ solution at $300 \mathrm{~K}$ with various concentrations of stearamidine.

\begin{tabular}{|c|c|c|c|c|c|c|c|}
\hline \multirow{2}{*}{ Stearamidine (mM) } & \multicolumn{2}{|c|}{ Tafel slopes } & \multirow{2}{*}{ Ecorr $(\mathrm{mV})$} & \multirow{2}{*}{ Icorr $\left(\mathrm{x} 10^{-6} \mathrm{~A} / \mathrm{cm}^{2}\right)$} & \multirow{2}{*}{$\Theta$} & \multirow{2}{*}{$\mathrm{CR}\left(\mathrm{mm} \mathrm{cm} \mathrm{c}^{-2} \mathrm{~h}^{-1}\right)$} & \multirow{2}{*}{ EI (\%) } \\
\hline & Cathode & Anode & & & & & \\
\hline Blank & $y=-0.004 x-3.960$ & $y=0.015 x-4.577$ & 32.47 & 81 & - & 0.00052 & 0.00 \\
\hline 0.06 & $y=-0.004 x-4.464$ & $y=0.013 x-3.766$ & -41.10 & 50 & 0.383 & 0.00032 & 38.27 \\
\hline 0.13 & $y=-0.005 x-5.079$ & $y=0.013 x-3.644$ & -79.72 & 21 & 0.741 & 0.00014 & 74.07 \\
\hline 0.19 & $y=-0.005 x-5.535$ & $y=0.013 x-4.759$ & -43.11 & 4.8 & 0.941 & 0.00003 & 94.07 \\
\hline 0.25 & $y=-0.005 x-5.778$ & $y=0.013 x-4.837$ & -52.28 & 3.0 & 0.963 & 0.00002 & 96.30 \\
\hline 0.31 & $y=-0.005 x-5.508$ & $y=0.012 x-4.741$ & -45.12 & 5.2 & 0.936 & 0.00003 & 93.58 \\
\hline
\end{tabular}

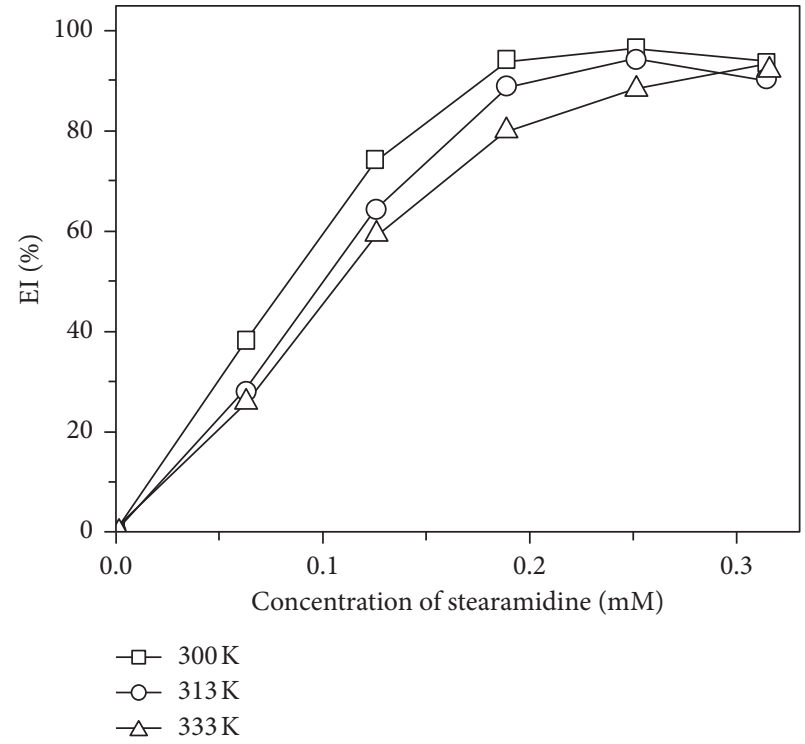

(a)

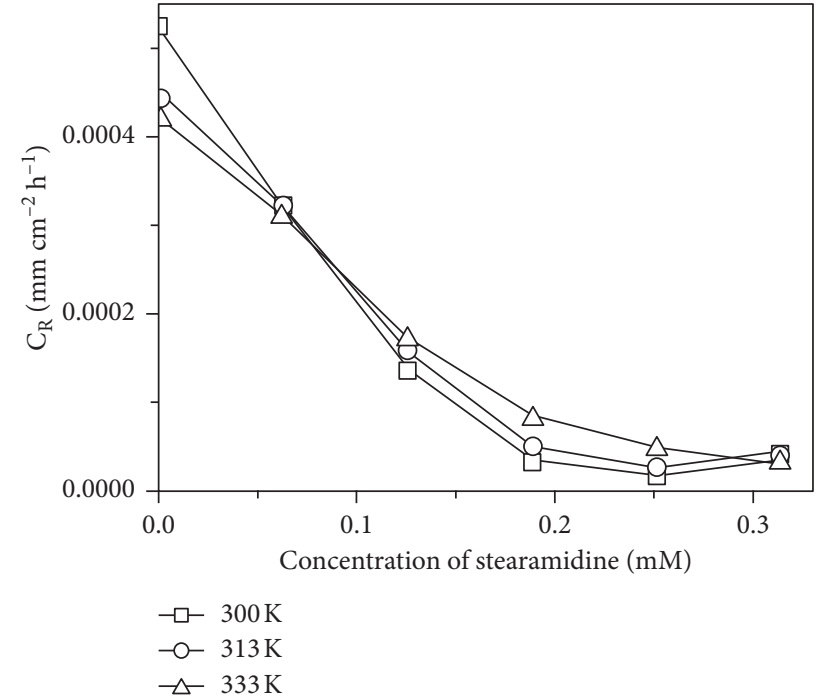

(b)

Figure 4: Inhibition efficiency (a) and corrosion rate (b) of copper as a function of the concentration of stearamidine in $3.0 \mathrm{wt} . \% \mathrm{NaCl}$ solution at $300-333 \mathrm{~K}$.

inhibitor enhances the metal resistance to corrosion. Figure 5(a) shows that the oxidation reaction occurs at the surfaces of copper, leading to the rupture of metal structure initiated by microporous formations on its surfaces. On the other hand, by addition of stearamidine, the surface of copper is well-protected from oxidation (Figure 5(b)).

3.2. Isotherms of Adsorption. It is essential to evaluate the adsorption isotherm to reveal the inhibition mechanism of stearamidine on copper surfaces. Based on data fitting with well-known isotherm models (i.e., Langmuir, Frumkin, Freundlich, and Temkin) [36], it was found that the inhibition of stearamidine followed the Langmuir-type adsorption. The equation of Langmuir adsorption is as follows:

$$
\frac{[\mathbf{C}]}{\boldsymbol{\theta}}=\frac{1}{\mathbf{K}_{\mathrm{ads}}}-[\mathbf{C}],
$$

where the surface coverage is $\theta$, the adsorptive equilibrium constant is $\mathrm{K}_{\mathrm{ads}}$, and the concentration of stearamidine is $[\mathrm{C}]$. $[\mathrm{C}] / \theta$ as a function of $[\mathrm{C}]$ at three different temperatures
$(300,313$, and $333 \mathrm{~K})$ is shown in Figure 6. The $\mathrm{K}_{\mathrm{ads}}$ value of stearamidine for each temperature was estimated from the linearly fitted curve reported in Figure 6 . The estimated $K_{a d s}$ at different temperatures are summarized in Table 2.

To determine the free energy parameter of the stearamidine adsorption on the copper surface $\left(\Delta \mathbf{G}_{\mathrm{ads}}^{0}\right)$, we used the following relation:

$$
\Delta \mathbf{G}_{\mathrm{ads}}^{0}=-\mathbf{R T} \ln \left(55.5 \mathbf{K}_{\mathrm{ads}}\right),
$$

where $T$ is the absolute temperature $(\mathrm{K})$ and $R$ is the universal gas constant, and the concentration of water used in the solution is 55.5. Table 2 provided the value of calculated $\Delta \mathbf{G}_{\text {ads }}^{0}$ that is in the range of -31.61 to $-35.29 \mathrm{~kJ} \mathrm{~mol}^{-1}$. These negative values indicate that the adsorption phenomenon, where a stable molecular layer of stearamidine on the copper surface is formed, is a spontaneous process. It is reported that the type of adsorption is regarded as physisorption if the $\Delta \mathbf{G}_{\text {ads }}^{0}$ values are below $-20 \mathrm{~kJ} \mathrm{~mol}^{-1}$. At this level, the inhibition activity is mainly dominated by Coulombic interactions. On the other hand, if the $\Delta \mathbf{G}_{\text {ads }}^{0}$ values are higher than $40 \mathrm{~kJ} \mathrm{~mol}^{-1}$, the adsorptions are predominately by chemisorption process [35]. Therefore, by evaluating $\Delta \mathbf{G}_{\mathrm{ads}}^{0}$, 

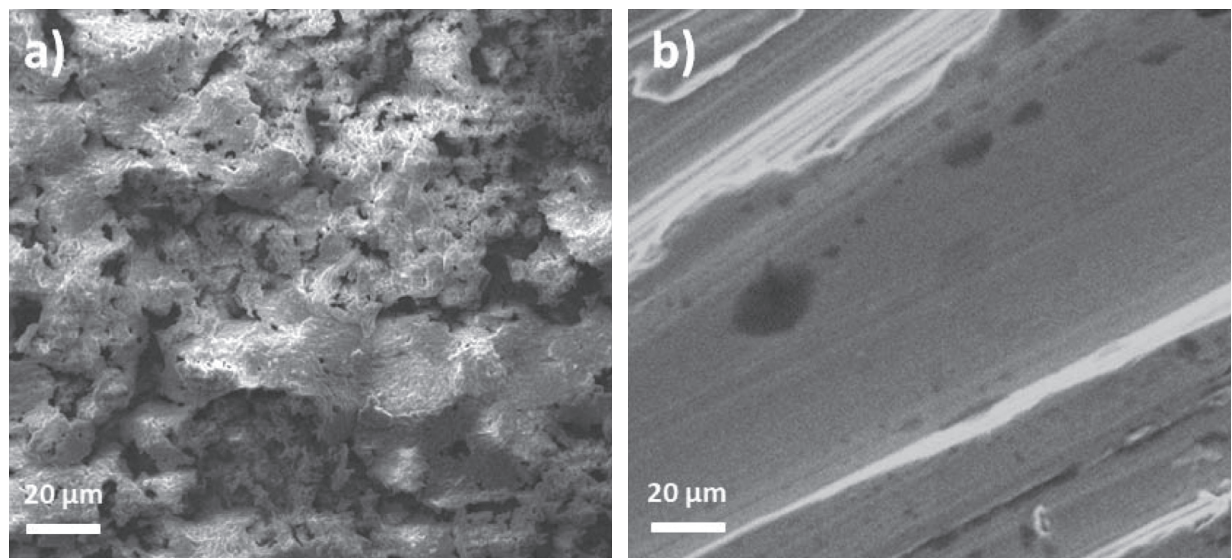

FIGURE 5: SEM micrographs of copper surfaces (250x magnitude). (a) Copper surface without corrosion inhibitor. (b) Copper surface with corrosion inhibitor at optimum condition $(0.2 \mathrm{mM}$ stearamidine, $300 \mathrm{~K})$.

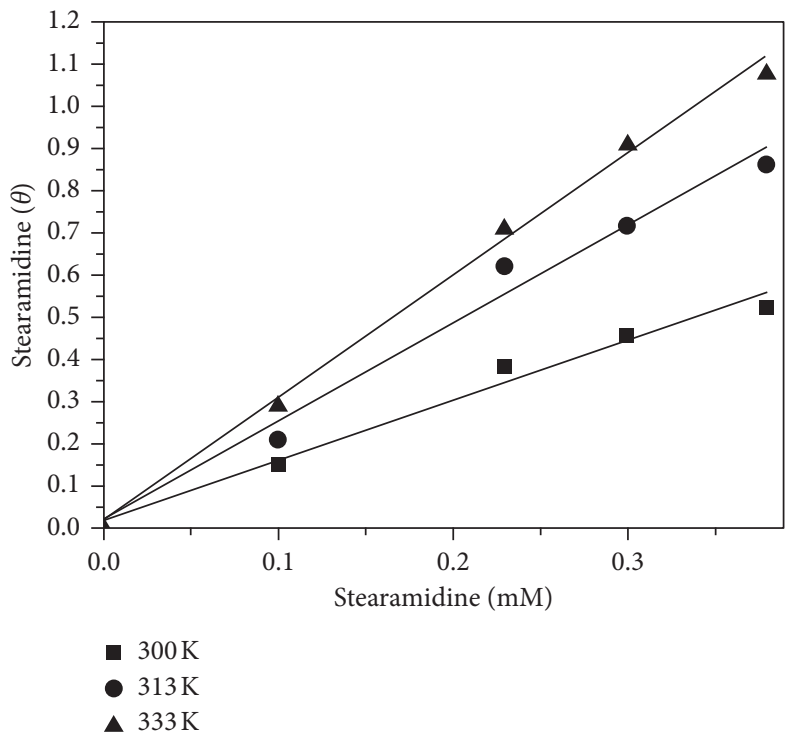

FIgURE 6: Langmuir-type adsorption isotherms of stearamidine in $1 \mathrm{wt} . \% \mathrm{NaCl}$ solution at 300-333 K.

TABLE 2: Calculated thermodynamic parameters of the interaction between stearamidine and copper surface in $3.0 \mathrm{wt} . \% \mathrm{NaCl}$ solution at $300-333 \mathrm{~K}$.

\begin{tabular}{lcccccc}
\hline Compound & $T(\mathrm{~K})$ & $R$ & $\mathrm{~K}_{\mathrm{ads}}\left(\mathrm{L} \mathrm{mol}^{-1}\right)$ & $\Delta G^{0}\left(\mathrm{~kJ} \mathrm{~mol}^{-1}\right)$ & $\Delta H^{0}\left(\mathrm{~kJ} \mathrm{~mol}^{-1}\right)$ & $\left.\Delta S^{0}(\mathrm{~J} \mathrm{~mol})^{-1}\right)$ \\
\hline \multirow{3}{*}{ Stearamidine } & 300 & 0.999 & 5777.01 & -31.61 & -11.86 \\
& 313 & 0.992 & 4037.14 & -32.05 & 36.28 & -11.36 \\
& 333 & 0.998 & 6222.78 & -35.29 & 38.59 & -10.68 \\
\hline
\end{tabular}

the stearamidine can be classified as a mixed-type inhibitor in which its adsorption on copper surfaces involves physisorption and chemisorption processes.

\section{Conclusions}

Fatty amidine has been evaluated as a potential corrosion inhibitor for copper using strearamidine as a model molecule. Stearamidine hydrochloride is successfully synthesized from stearic acid (yield 88\%). Based on SEM images and potentiodynamic measurements, stearamidine shows excellent potential as a corrosion inhibitor for copper in 3.0 wt.\% $\mathrm{NaCl}$ solution. Corrosion inhibition of stearamidine follows Langmuir-type adsorption isotherm, involving both physisorption and chemisorptions. It is observed that the maximum corrosion inhibition efficiency (96\%) is achieved for $0.2 \mathrm{mM}$ stearamidine in $3.0 \mathrm{wt} . \% \mathrm{NaCl}$ solution at $300 \mathrm{~K}$.

\section{Data Availability}

The data used to support the findings of this study are available from the corresponding author on request. 


\section{Conflicts of Interest}

The authors declare no conflicts of interest.

\section{Acknowledgments}

ND acknowledges support from the BPDPKS Research Grant Project (no.PRJ- 70/DPKS/2018).

\section{References}

[1] M. M. Antonijevic and B. M. Petrovic, "Copper corrosion inhibitors. a review," International Journal of Electrochemical Science, vol. 3, pp. 1-28, 2008.

[2] G. Tansuğ, T. Tüken, S. E Giray et al., "A new corrosion inhibitor for copper protection," Corrosion Science, vol. 84, pp. 21-29, 2014.

[3] B. M. Petrović Mihajlović and M. M. Antonijević, "Copper corrosion inhibitors. period 2008-2014. A review," International Journal of Electrochemical Science, vol. 10, pp. 10271053, 2015.

[4] A. Fateh, M. Aliofkhazraei, and A. R. Rezvanian, "Review of corrosive environments for copper and its corrosion inhibitors," Arabian Journal of Chemistry, vol. 13, no. 1, pp. 481-544, 2020.

[5] R. Gašparac, R. C. Martin, and E. Stupnišek-Lisac, "In situ studies of imidazole and its derivatives as copper corrosion inhibitors I. Activation energies and thermodynamics of adsorption," Journal of The Electrochemical Society, vol. 147, pp. 548-551, 2000.

[6] I. Lukovits, E. Kálmán, and F. Zucchi, "Corrosion inhibitors correlation between electronic structure and efficiency," Corrosion, vol. 57, pp. 3-8, 2001.

[7] M. Finšgar and I. Milošev, "Inhibition of copper corrosion by 1, 2, 3-benzotriazole. a review," Corrosion Science, vol. 52, pp. 2737-2749, 2010.

[8] H. Tian, F. Y. Cheng, W. Li, and B. Hou, "Triazolyl-acylhydrazone derivatives as novel inhibitors for copper corrosion in chloride solutions," Corrosion Science, vol. 100, pp. 341-352, 2015.

[9] H. Bi, T. G. Burstein, B. B. Rodriguez, and G. Kawaley, "Some aspects of the role of inhibitors in the corrosion of copper in tap water as observed by cyclic voltammetry," Corrosion Science, vol. 102, pp. 510-516, 2016.

[10] B. V. Appa Rao and M. Narsihma Reddy, "Formation, characterization and corrosion protection efficiency of selfassembled 1-octadecyl-1H-imidazole films on copper for corrosion protection," Arabian Journal of Chemistry, vol. 10, pp. S3270-S3283, 2017.

[11] B. M. Petrović Mihajlović, B. M. Radovanović, Z. Z. Tasić, and M. M. Antonijević, "Imidazole based compounds as copper corrosion inhibitors in seawater," Journal of Molecular Liquids, vol. 225, pp. 127-136, 2017.

[12] M. E. Sherif and M. S. Park, "2-amino-5-ethyl-1,3,4-thiadiazole as a corrosion inhibitor for copper in $3.0 \% \mathrm{NaCl}$ solutions," Corrosion Science, vol. 48, pp. 4065-4079, 2006.

[13] F. Zucchi, G. Trabanelli, and M. Fonsati, "Tetrazole derivatives as corrosion inhibitors for copper in chloride solutions," Corrosion Science, vol. 38, pp. 2019-2029, 1996.

[14] A. M. Elsharif, S. A. Abubshait, I. Abdulazeez, and H. A. Abubshait, "Synthesis of a new class of corrosion inhibitors derived from natural fatty acid: 13-Docosenoic acid amide derivatives for oil and gas industry," Arabian Journal of Chemistry, vol. 13, no. 5, pp. 5363-5376, 2020.
[15] B. P. Raja and G. M. Sethuraman, "Natural products as corrosion inhibitor for metals in corrosive media - a review," Materials Letters, vol. 62, pp. 113-116, 2008.

[16] H. Gerengi and I. H. Sahin, "Schinopsis lorentzii extract as a green corrosion inhibitor for low carbon steel in $1 \mathrm{M} \mathrm{HCl}$ solution," Industrial \& Engineering Chemistry Research, vol. 51, pp. 780-787, 2012.

[17] S. F. De Souza and A. Spinelli, "Caffeic acid as a green corrosion inhibitor for mild steel," Corrosion Science, vol. 51, pp. 642-649, 2009.

[18] G. Moretti, F. Guidi, and G. Grion, "Tryptamine as a green iron corrosion inhibitor in $0.5 \mathrm{M}$ deaerated sulphuric acid," Corrosion Science, vol. 46, pp. 387-403, 2004.

[19] U. Biermann, U. Bornscheuer, R. A. M. Meier, O. J. Metzger, and J. H. Schäfer, "Oils and fats as renewable raw materials in chemistry," Angewandte Chemie International Edition, vol. 50, pp. 3854-3871, 2011.

[20] R. N. P. Vennestrøm, M. C. Osmundsen, H. C. Christensen, and E. Taarning, "Beyond petrochemicals: the renewable chemicals industry," Angewandte Chemie International Edition, vol. 50, pp. 10502-10509, 2011.

[21] M. B. Badran, A. A. Abdel Fattah, and A. A. Abdul Azim, "New corrosion inhibitors based on fatty materials-I. epoxidized fatty materials modified with aliphatic amines," Corrosion Science, vol. 22, pp. 513-523, 1982.

[22] A. M. Quraishi, D. Jamal, and N. R. Singh, "Inhibition of mild steel corrosion in the presence of fatty acid thiosemicarbazides," Corrosion, vol. 58, pp. 201-207, 2002.

[23] R. Martínez-Palou, J. Rivera, G. L. Zepeda et al., "Evaluation of corrosion inhibitors synthesized from fatty acids and fatty alcohols isolated from sugar cane wax," Corrosion, vol. 60, pp. 465-470, 2004.

[24] A. M. Quraishi and D. Jamal, "Fatty acid triazoles: novel corrosion inhibitors for oil well steel (N-80) and mild steel," Journal of The Electrochemical Society, vol. 77, pp. 1107-1111, 2000.

[25] H. S. Yoo, W. Y. Kim, K. Chung, Y. S. Baik, and S. J. Kim, "Synthesis and corrosion inhibition behavior of imidazoline derivatives based on vegetable oil," Corrosion Science, vol. 59, pp. 42-54, 2012.

[26] A. Yildirim and M. Çetin, "Synthesis of undecanoic acid phenylamides as corrosion inhibitors," European Journal of Lipid Science and Technology, vol. 110, pp. 570-575, 2008.

[27] S. Ghareba and S. Omanovic, "Interaction of 12-aminododecanoic acid with a carbon steel surface: towards the development of "green" corrosion inhibitors," Corrosion Science, vol. 52, pp. 2104-2113, 2010.

[28] N. Ochoa, F. Moran, N. Pébère, and N. Tribollet, "Influence of flow on the corrosion inhibition of carbon steel by fatty amines in association with phosphonocarboxylic acid salts," Corrosion Science, vol. 47, pp. 593-604, 2005.

[29] A. M. Quraishi and A. F. Ansari, "Fatty acid oxadiazoles as corrosion inhibitors for mild steel in formic acid," Journal of Applied Electrochemistry, vol. 36, pp. 309-314, 2006.

[30] A. Yildirim and M. Çetin, "Synthesis and evaluation of new long alkyl side chain acetamide, isoxazolidine and isoxazoline derivatives as corrosion inhibitors," Corrosion Science, vol. 50, pp. 155-165, 2008

[31] S. Öztürk, A. YildIrIm, M. Çetin, and M. TavaslI, "Synthesis of quaternary, long-chain $\mathrm{N}$-alkyl amides and their corrosion inhibition in acidic media," Journal of Surfactants and Detergents, vol. 17, pp. 471-481, 2014.

[32] P. G. Moss, S. A. P. Smith, and D. Tavernier, "Glossary of class names of organic compounds and reactive intermediates 
based on structure (IUPAC recommendations 1995)," Pure and Applied Chemistry, vol. 67, pp. 1307-1375, 1995.

[33] B. R. Perkins, J. J. Roden, and H. E. Pryde, "Nylon-9 from unsaturated fatty derivatives: preparation and characterization," Journal of the American Oil Chemists' Society, vol. 52, pp. 473-477, 1975.

[34] L. P. Barker, L. P. Gendler, and H. Rapoport, "Acylation of dibasic compounds containing amino amidine and aminoguanidine functions," The Journal of Organic Chemistry, vol. 46, pp. 2455-2465, 1981.

[35] Z. Cheng, S. Mo, J. Jia, J. Feng, Q. H. Luo, and B. N. Li, "Experimental and theoretical studies of 4, 6-diamino-2mercaptopyrimidine as a copper inhibitor in $3.5 \mathrm{wt} \% \mathrm{NaCl}$ solution," RSC Advances, vol. 6, pp. 15210-15219, 2016.

[36] F. Bentiss, M. Traisnel, and M. Lagrenee, "The substituted 1, 3, 4-oxadiazoles: a new class of corrosion inhibitors of mild steel in acidic media," Corrosion Science, vol. 42, pp. 127-146, 2000. 